\title{
Memories of Sir Wilfred Cockcroft 1923-1999
}

\section{TONY CRILLY}

Brolly aloft, hailing a London cab outside the Athenaeum Club in 1998, that was Sir Wilfred Cockcroft the last time I saw him. The first time, almost 40 years previously, was in a class of seventy undergraduates where the energetic new professor was teaching complex numbers and gaining his initial experience of Hull University. The institution was expanding and the two new professors (Noel Slater being the other) replaced a more sedate regime.

Bill Cockcroft gave the impression of a figure somewhere between a modern business type and a scholar. His pragmatism and aptitude for getting things done was at variance with the figure decked out in academic gown topped off with a perilously perched mortar-board who performed in the lecture room. His trademark bow tie reminded us, and probably him, of his Oxford background. A few weeks into his period at Hull, he came to a crowded student bash and was favourably received for his party-piece based on the mathematical ploys for catching lions in the Sahara (e.g. by an inversion by which the lion is mapped into the cage, and so is everyone else). It was pure theatre and he was in his element.

I knew him better when I was a postgraduate student studying for a MSc in algebraic topology. Being an ambitious university politician, 'Cockers' left the two of us to our own devices most of the time but he did provide a crash course on things like 'short exact sequences', the 'five-lemma', and chasing around algebraic diagrams. The course took place in his office which was a revamped gardener's outbuilding tacked on to residential house in Newland Park, then the Hull Department of Pure Mathematics. That confined space was almost like being in the lion's den at times. Nose to nose he would tell you with great excitement that so and so 'was what you always thought it was' or something was true 'by naturality' or 'all this goes through by the usual argument.' His enthusiasm for mathematics was contagious. Looking back, the course for two was quite formal, with him chalking on a postage-stamp blackboard and us taking notes. He looked upon the hour as a break from the mountains of administration piled on his desk, I fancy.

Bill was an intuitive mathematician but the 1960 s Bourbakian mission and 'structure' was always high on his agenda. He revelled in the exotic constructions in algebraic topology like 'mapping cylinders', 'dunce's hat', suspension spaces, and competing theories especially when they involved people or controversy. Thus the 'singular theory' was pitted against the 'simplicial' and the 'cubical'... and the like. We heard a lot about 'CW complexes' and how a certain topological space was really a 'bouquet of spheres'. Abstraction piled on abstraction was treated to a Cockcroftian proclamation about 'Categories and Functors and all that nonsense'. When 
you asked him whether such and such was really proved, he would turn it round and ask "Can you stand with hand on heart and say "yes, it is true", as if faith somehow provided the acid test. He also offered us little asides on how to study like his incisive '9.30-12.30 rule' by which one had to concentrate $100 \%$ during the morning, no matter what happened for the rest of the day. Another cure for procrastination was his recommendation to 'sit down and just do it'.

Symptomatic of Bill's infectious manner was how he would go along with a joke or a story. All the time he would encourage with his insistent 'yes, yes, yes...'. This sequence gained in rapidity until he either capped the story himself, or, failing that, acquiesced in it being 'nice'. If a mathematical result went against intuition, he would feign a startled look, declaring 'really ... how curious, how very odd, ... yes very odd', all at 10 decibels. He would sometimes line up his students to baby-sit his and Rhona's two young boys ('just come-beer provided') and on the journey in his worn out old car the talk was of mathematics, punctured with a whimsical 'curious', or 'I just don't know' or a story about some mathematician or other. Polar extremes were the best like his assessment of the Eilenberg-Steenrod partnership in which Norman Steenrod's slow thoughtfulness was contrasted with 'Sammy' Eilenberg's mercurial mind. For tea in the Cockcroft semi we would have home-grown sweet corn though the Hull climate limited the success of this agrarian venture.

Through Bill's Royal Air Force connections he sometimes came along to social evenings at the University Air Squadron. If the conversation flagged or he became bored he would haul me outside and leaning on the staircase, let me know his latest thoughts on a problem for a possible research topic. The 'Implicit Function theorem' was the way to look at it, he would broadcast to all, before catching the eye of an acquaintance. Drawn back to the bar, he would leave me with a loud instruction to write it all down on a large piece of paper. After a late night socializing, he had a remarkable gift for recovery. At a seminar the next morning he would have the happy knack of being able to ask the first question following a restful period during the talk itself. He was invariably positive in outlook. On hearing there would be a Colloquium at St Andrews his instant advice was 'just go there' and he offered the same guidance when it came to studying in the USA after Hull.

Like many mathematicians Bill Cockcroft received his impetus to study mathematics from one particular school teacher, a Mr Capstick (if memory serves) at Keighley Grammar School. This gentleman was not only an excellent teacher but knew his way around the Oxbridge scholarship system. At Oxford, Bill was a DPhil student of J. H. C. Whitehead who he thought the right supervisor for one who really wanted to be a mathematician. There he developed his head-on way of attacking a mathematical problem,-- 'to hit it in the guts'-was how he expressed it to me. He was a student of René Thom's work and attended a meeting in France where he met the mathematician. In research he advised to go on from known work and not 
spend time reinventing the wheel, although I think this view softened later on.

On learning that Paul Halmos was coming to Britain to lecture in 1995, I was commanded to attend. Bill would be in France but he wrote: 'Don't miss him! He's still, in my opinion, the best lecturer (at least in English) in the world, when he's on form.' Bill's interest in mathematical education was always evident and he was one of the first to present mathematics on television (around 1964). He took real delight in things like young children measuring the area of a leaf by counting squares since they were really doing integration. At Hull he struck up a liaison with Professor Frank Land from the Education department and laid on courses for local school teachers to find out about modern mathematics.

The most fruitful part of his professional life, by his own admission, was his work on the Report which bears his name and the subsequent setting up of the GCSE. He told me that he asked Keith Joseph, whom he much admired, why he had to work with such outspoken right and left-wingers on the committees. Joseph told him that the overriding qualification for membership was their commitment to the education of children, and political persuasion was of very little importance. From his telling of this story, it was a sentiment with which he fully agreed.

Lunch at the Athenaeum Club was not quite my last point of contact. When he bought a computer from a company in Hertfordshire, he had occasion to call me up. He was very proud of his new purchase with its 'Lotus Smart Suite' and all the other bells and whistles. However he felt some components were missing. His solution to the dilemma was characteristic of all movers and shakers. There was a problem so who do I know near St Albans? I was duly appointed local agent and learned to recognize that booming voice down the telephone for a few weeks. I felt very privileged and it was a very small part to put on my side of the balance. I shall remember him for many personal kindnesses at Hull and for taking an interest in my early career. Readers will find some little gems in the Reviews Section of the Gazette, all done on his new computer.

TONY CRILLY 10 Lemsford Road, St Albans, Hertfordshire AL1 3PB 